\title{
Utilization of information technology-based learning media for supporting active learning activities at Middle School (SMP) Negeri 2 Pantai Labu
}

\author{
M.R. Syahputra ${ }^{1 *}$, Mardiningsih ${ }^{1}$, Isnaini Halimah Rambe ${ }^{2}$ \\ ${ }^{1}$ Department of Mathematics, Faculty of Mathematics and Science, Universitas Sumatera \\ Utara, Medan, Indonesia \\ ${ }^{2}$ Mathematics Education, Faculty of Teacher Training and Education, Universitas Islam \\ Sumatera Utara, Indonesia \\ *Email: m.romi@usu.ac.id
}

\begin{abstract}
The community service that will be carried out in this research is entitled "The Use of Information TechnologyBased Learning Media to Support Active Learning Activities in Junior High School (SMP) Negeri 2 Pantai Labu", with the aim of helping teachers in a more interesting, interactive and learning process. fun. In this service activity, teachers will be equipped with the ability to make teaching materials based on information technology. Not only that, teachers will also be equipped with teaching aids that will support active learning activities in schools that can be used for learning mathematics and science. This activity is expected to increase interest in learning and the achievement of teachers and students at SMP Negeri 2 Pantai Labu.
\end{abstract}

Keywords: Online, Information Technology, Community Service

\begin{abstract}
Abstrak
Pengabdian kepada masyarakat yang akan dilakukan pada penelitian ini berjudul "Pemanfaatan Media Belajar Berbasis Teknologi Informasi Untuk Mendukung Kegiatan Pembelajaran Aktif Di Sekolah Menengah Pertama (SMP) Negeri 2 Pantai Labu", dengan tujuan membantu guru-guru dalam proses pembelajaran yang lebih menarik, interaktif dan menyenangkan. Pada kegiatan pengabdian ini, guru-guru akan dibekali dengan kemampuan membuat bahan ajar berbasis teknologi informasi. Tak hanya itu, guru juga akan dibekali dengan alat peraga yang akan mendukung kegiatan pembelajaran aktif di sekolah yang dapat digunakan untuk pembelajaran matematika dan IPA. Kegiatan ini diharapkan dapat meningkatkan minat belajar serta prestasi guru dan siswa di SMP Negeri 2 Pantai Labu.
\end{abstract}

\section{Kata Kunci: Daring, Teknologi Informasi, Pengabdian}

\section{PENDAHULUAN}

Dalam hal mencari solusi untuk mengatasi masalah tersebut, sehingga dapat meningkatkan minat belajar dan prestasi belajar siswa pada pelajaran matematika. Dalam kegiatan belajar mengajar ketidakjelasan dan banyaknya materi yang disampaikan dapat dibantu dengan menghadirkan media sebagai perantara. Kerumitan bahan pelajaran dapat disederhanakan dengan bantuan media, karena media dapat mewakili apa yang kurang mampu disampaikan melalui kata-kata atau kalimat. Oleh karena itu dalam rangka membantu meningkatkan mutu pendidikan dan pengajaran matematika khususnya, maka perlu memanfaatkan perkembangan teknologi komputer.

Di dunia komputer dikenal istilah animasi. Animasi merupakan salah satu bagian grafika komputer yang menyajikan tampilan yang sangat atraktif. Pemanfaatan animasi dapat ditujukan untuk simulasi, menarik perhatian pemakai komputer pada bagian tertentu pada layar, menampilkan keluaran program dengan gambar-gambar yang menarik dibandingkan dengan sederetan angka atau huruf. Dengan adanya aplikasi ini diharapkan dapat memudahkan dam menyenangkan dalam memahami dan mempelajari materi yang diberikan oleh guru. 
Penggantian sistem ini diharapkan dapat memberikan informasi yang akurat, menghemat biaya dan waktu, sehingga dalam proses belajar mengajar seluruh siswa dapat mengerti materi pelajaran tersebut. Begitu juga perancangan animasi ini dapat memberikan motivasi terhadap siswa dalam hal pembelajaran matematika khususnya masalah bangun bidang dan ruang.

\section{METODE PELAKSANAAN}

Kegiatan ini akan dilaksanakan pada kurun waktu Bulan Juni sampai dengan Bulan September dengan memberikan pelatihan bagi guru-guru SMP dengan tujuan agar guru dapat melaksanakan kegiatan belajar mengajar menggunakan metode pembelajaran aktif. Pelaksana pengabdian akan memberikan pelatihan tentang penyiapan Rencana Proses Pembelajaran berbasis Pembelajaran Aktif. Selanjutnya juga diberikan pelatihan Pembuatan Bahan Ajar yang berbasis Teknologi Informasi dan Komunikasi, baik menggunakan Power Point maupun penyiapan bahan berbentuk video pembelajaran. Untuk keberlangsungan dari pelatihan yang diberikan, mitra akan diberikan perangkat komputer beserta infokus/proyektor. Hal ini bertujuan agar metode pembelajar aktif di kelas dapat diteruskan.

Pelaksanaan Pengabdian ini akan dilakukan dalam dua tahapan besar, yaitu:

1. Pelaksanaan Forum Group Discussion (FGD) serta Pelatihan Penyiapan RPP

FGD dilaksanakan untuk curah pendapat yang akan memberikan masukan kepada Pelaksana Pengabdian terkait masalah-masalah utama di SMP Negeri 2 Pantai Labu. Kegiatan ini dilanjutkan dengan pelatihan penyiapan RPP yang dihadiri oleh semua guru di SMP Negeri 2 Pantai Labu. Tujuannya agar para guru dapat menyusun RPP berbasis pembelajaran aktif. Kegiatan ini akan dilakukan oleh Pelaksana Pengabdian sendiri. Kegiatan akan dilaksanakan pada Bulan Juli 2020.

2. Pelatihan Pembuatan Bahan Ajar berbasis Teknologi Informasi.

Pelatihan ini akan difokuskan kepada Guru Mata Pelajaran dengan bidang masing-masing. Peserta pelatihan dikelompokkan ke dalam beberapa kelompok, sehingga bisa fokus langsung menggunakan komputer. Kegiatan ini akan dilaksanakan pada bulan Agustus atau September 2020 .

Metode yang akan dilakukan pada pelaksanaan pengabdian ini adalah :

1. Mengumpulkan informasi yang diambil dari buku atau kurikulum pelajaran yang akan dibuat aplikasi pembelajarannya.

2. Melakukan identifikasi bagaimana membuat agar materi yang dikaji menjadi lebih mudah dipelajari oleh siswa SMP.

3. Untuk menarik minat belajar siswa pada materi ini, akan dibuat aplikasi pembelajaran yang materinya dikemas seefisien mungkin, sehingga siswa dapat berinteraksi dengan aplikasi tersebut.

4. Melakukan perancangan aplikasi pembelajaran, mulai dari membuat tampilan aplikasi, penyusunan materi, latihan dan soal.

5. Setelah perancangan rampung dan diperoleh hasil yang maksimal, maka dilakukan pembagian aplikasi ini ke sekolah dan membuat pelatihan /workshop kepada guru matematika atau siswa.

\section{HASIL DAN PEMBAHASAN}

Kegiatan pengabdian dilaksanakan oleh tim pada minggu ke 3 September 2020, tepatnya tanggal 15 September 2020. Kegiatan ini seyogyannya akan dihadiri oleh 20 orang guru, namun karena cuaca yang kurang mendukung mengakibatkan hanya sekitar 13 orang guru yang turut hadir pada kegiatan tersebut. Namun demikian, pelaksanaan kegiatan ini terbilang cukup mengambil perhatian para guru dalam mengikuti rangkaian demi rangkaian kegiatan. Terlihat dari antusiasme para guru dalam belajar membuat pembelajaran jarak jauh/ pembelajaran online yang disampaikan oleh tim pelaksana melalui narasumber yang diundang. 


\section{Focus Group Discussion (FGD)}

Kegiatan FGD bertujuan untuk melakukan diskusi awal dalam mempelajari dan mengetahui perkembangan sekolah didalam melaksanakan pembelajaran untuk siswa/i di SMP Negeri 2 Pantai Labu. Kegiatan dihadiri oleh Kepala Sekolah SMP Negeri 2 Pantai Labu, Guru, pegawai Tata Usaha, dan Orang tua murid. Kegiatan dibuka oleh ketua Tim Pengabdian Pada Masyarakat dan di bawakan oleh anggota Tim pengabdian pada masyarakat.

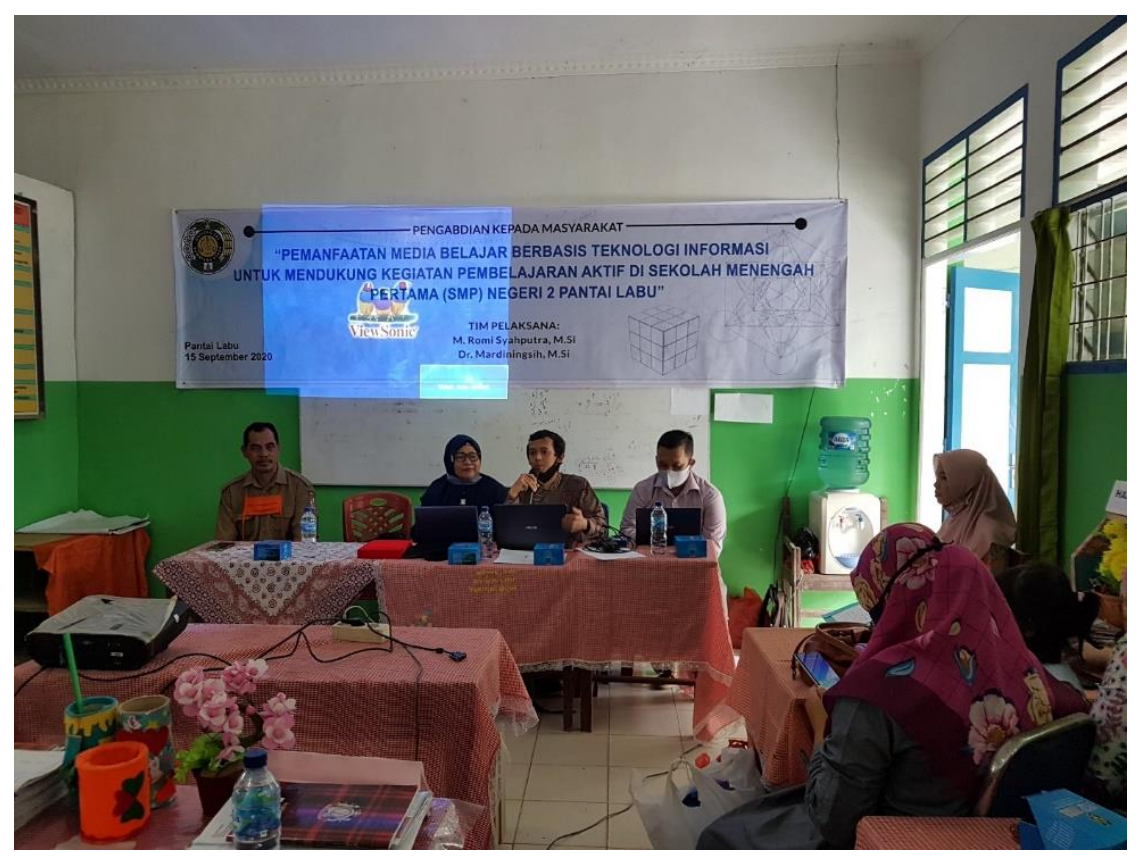

Gambar 1 . Kata Sambutan Ketia Tim Pengabdian USU

\section{Pelatihan Pembelajaran Aktif di Sekolah}

Pada tahap kedua telah dilakukan pelatihan di dalam pelatihan pembelajaran aktif di sekolah secara daring yang ditujukan kepada guru dan staf SMP Negeri 2 Pantai Labu. Pelatihan dipimpin langsung oleh ketua Tim dalam memberikan metode pembelajaran yang berbeda yang dapat di terapkan kepada siswa/i di sekolah. Pelatihan yang dilakukan diharapkan mampu memberikan edukasi kepada para guru supaya tidak melupakan nilai-nilai yang harus dilakukan disetiap kegiatan belajar mengajar yang akan dilakukan seperti mengucap salam, berdoa, menyanyikan lagu bernuansa Nasionalisme dan nilai-nilai Pancasila ditengah-tengah kehidupan bermasyarakat. 


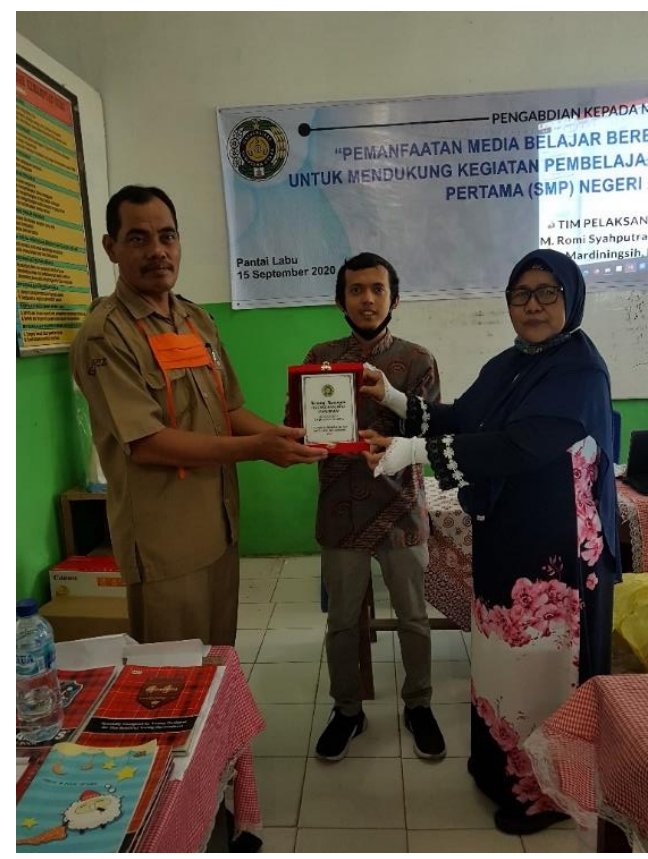

Gambar 2. Serah Terima Perangkat Pendukung Pembelajaran Aktif di Sekolah

\section{KESIMPULAN (CONCLUSION)}

Dari semua kegiatan pengabdian kepada masyarakat yang dilakukan dapat disimpulkan bahwa kegiatan ini sangat penting dilakukan karena banyak hal positif yang dihasilkan. Dari kegiatan pertama yaitu Focus Group Discussion diperoleh banyak masukan dan saran dalam memperbaiki keadaan pendidikan di Indonesia. Tetapi banyak hambatan yang membuat setiap saran dapat terlambat dalam pelaksanaanya. Sarana dan prasarana yang kurang memadai dalam melakukan kegiatan belajar dan mengajar. Serta keterlibatan alumni dalam membantu membangun dan mengembangkan SMP N 2 Pantai Labu.

Untuk kegiatan kedua yaitu pemberian materi pembelajaran aktif serta pemberian sarana pembelajaran sesuai hasil FGD dapat dilihat keinginan untuk mengembangkan sekolah sangat tinggi. Dapat dilihat dari keinginan belajar guru dan staf supaya dapat menerapkan pembelajaran aktif di SMP N 2 Pantai Labu. Dan dilanjutkan kegiatan ketiga yaitu pemberian materi untuk menerapkan pembelajaran aktif berbasis teknologi informasi dan komunikasi untuk menyempurnakan pembelajaran aktif berbasis TIK.

Dari ketiga kegiatan tersebut, kesimpulan yang dapat diambil adalah kegiatan pengabdian masyarakat untuk pembelajaran aktif dan TIK sebaiknya diperbanyak dikarenakan masih banyak sekolah yang belum menerapkannya. Sedangkan dari kemajuan zaman yaitu Industri 4.0, pembelajaran berbasis TIK sangat diperlukan. Saran untuk pengabdian berikutnya yaitu pembelajaran berbasis TIK bisa dibuat dengan suatu program supaya lebih memberikan bentuk ilmu pengetahuan.

\section{UCAPAN TERIMAKASIH}

Terimakasih kepada Rektor USU dan LPPM USU yang telah memberikan dana pengabdian tahun 2020 Skema Profesor mengabdi. 
M.R. Syahputra, et al Utilization of information technology-based learning media

\section{DAFTAR PUSTAKA}

HomeEdition. 2005, Macromedia flash Profesional 8 help, Macromedia Inc

Juhaeri. 2009. Pengantar Multimedia untuk Media Pembelajaran bagian I, Ilmu Komputer.

Retno, Margono dan Bambang Eka Purnama. ISSN 1979 - 9330. Study of Interaktif Recognition Letter and Number For Children With Computer Multimedia. Indonesian jurnal on Computer Science - Speed (IJCSS) 4 Vol. 3 Nomor 1 Agustus 2008

Script Island. 2008. Panduan Mudah Membuat Animasi. Jakarta: Media Kita.

Tulus, Sawaluddin, T.J. Marpaung, dan M.R. Syahputra. 2018. Making Learning Teaching Materials in School Based On Information And Communication Technology. Abdimas Talenta. Vol. 3 No. 2 pp. $202-2016$ 